J. AMER. Soc. HorT. SCI. 118(3):343-349. 1993.

\title{
Changes in the Physico-chemical Properties of Peach Fruit Pectin during On-tree Ripening and Storage
}

\author{
M.L. Fishman ${ }^{1}$, B. Levaj', and D. Gillespie ${ }^{3}$ \\ U.S. Department of Agriculture, Agricultural Research Service, Eastern Regional Research Center, 600 \\ East Mermaid Lane, Philadelphia, PA 19118 \\ R. Scorza ${ }^{4}$ \\ U.S. Department of Agriculture, Agricultural Research Service, Appalachian Fruit Research Station, 45 \\ Whitshire Road, Kearneysville, WV 25430
}

Additional index words. Prunus persica, intrinsic viscosity, molecular weight, radius of gyration, high performance size exclusion chromatography, cell walls

\begin{abstract}
Radius of gyration (size), intrinsic viscosity, molecular weight, percentage of galacturonate, and percentage of neutral sugars were measured for chelate-soluble (CSP) and alkaline-soluble (ASP) pectins extracted from the cell walls of melting flesh (MF) and nonmelting flesh (NMF) peach [Prunus persica (L.) Batsch]. Weight percentage of cell walls, pectin content, and firmness were measured also. Peaches were extracted at 20, 21, and 22 weeks after flowering (WAF) and after various lengths of shelf storage at $25 \pm 2 \mathrm{C}$ for the peaches picked at 21 WAF. Weight percentage of cell walls and firmness decreased markedly between the 21st and 22nd WAF; and between the 3rd and 6th day of storage for MF peaches as compared to NMF peaches. During these same periods, there were marked drops in the pectin content and the uronide content for MF as compared to NMF peaches. Size and intrinsic viscosity dropped markedly for CSP of MF peaches in comparison with NMF peaches during these same periods, whereas the molecular weight of CSP and ASP increased in MF peaches over that measured for NMF peaches. These results suggested that $\alpha$-D-galacturonase (E.C. 3.2.1.15) was involved in softening only in the latter stages of ripening MF peaches. Further, cell wall polymers containing long thin pectin aggregates were destroyed, whereas cell wall polymers containing short thick pectin aggregates remained.
\end{abstract}

Pectin plays a central role in the physiological and textural changes occurring in ripening fruits (Huber, 1983). The notion that correlating changes in pectin structure with maturity would aid in elucidating the mechanism of fruit softening at the molecular level, thereby enabling methods to be developed for maintaining the postharvest quality of peaches, has prompted numerous investigations of changes in pectic substances with peach ripening (Chapman and Horvat, 1990; Postylmayr et al., 1956; Pressey and Avants, 1978; Reeve, 1959; Shewfelt, 1965. Since MF (freestone) peaches soften appreciably more than NMF (clingstone) peaches, these two peach types have been chosen previously for comparative studies. Based upon historical evidence, Addoms et al. (1930) concluded that the flesh quality of nonmelting fruit was positively correlated with cell wall integrity which, in turn, resulted from a high content of insoluble pectin (sometimes referred to as protopectin). Pressey and Avants (1978) have demonstrated that peach softening is accompanied by conversion of water-insoluble to water-soluble pectin, and that a higher percentage of water-insoluble pectin is solubilized in MF than in NMF peaches. Furthermore, Pressey (1986) has shown that MF peaches possess an exo- and an endo- $\alpha$ D-galacturonase, whereas NMF peaches possess only an exo- $\alpha$ D-galacturonase. He concluded from these studies that endo$\alpha$ D-galacturonase was responsible for the increased pectin solubi-

Received for publication 24 Feb. 1992. Accepted for publication 19 Oct. 1992. M.L.F.'s present address: Macromolecular and Cell Structure Plant Science, USDA, ARS, Eastern Regional Research Center, 600 East Mermaid Lane, Philadelphia, PA 19118. Mention of brand or firm names does not constitute an endorsement by the U.S. Dept. of Agriculture over others of a similar nature not mentioned. The cost of publishing this paper was defrayed in part by the payment of page charges. Under postal regulations, this paper therefore must be hereby marked advertisement solely to indicate this fact.

${ }^{1}$ Research Chemist.

${ }^{2}$ Food Technologist.

${ }^{3}$ Chemist.

${ }^{4}$ Research Horticulturist. lization and softening of MF over NMF peaches.

The objective of our work was to further elucidate the softening processes in peaches by following changes in the physico-chemical properties of pectic substances (Fishman et al. 1991a, 1991b) during on-tree- and shelf-ripening of MF and NMF cultivars.

\section{M aterials and M ethods}

Plant material. About 20 to 30 MP ('Redskin') and NMF ('Suncling') peach fruit were hand picked weekly from 23 Aug. 1988 (20 WAF) to7 Sept. 1988 from trees grown at the Applachian Fruit Research Station, Agricultural Research Service, U.S. Dept. of Agriculture, Kearneysville, W.Va. One day after harvest, peaches were skinned, and the mesocarp was diced into small pieces and immediately immersed into liquid N. Frozen peach tissue was stored at $-20 \mathrm{C}$ in sealed polyethylene bags until analysis. Twenty 'Redskin' peaches and 17 'Suncling' peaches from those picked on 30 Aug. 1988 were kept at room temperature $(25 \pm 2 \mathrm{C})$. At intervals of 2, 4, and 6 days for 'Suncling' and 3, 6, and 9 days for 'Redskin', five peaches were diced and frozen. The exception was 'Redskin' peaches at 9 days, when only two were available.

Firmness measurement. Firmness was measured with one of two penetrometers depending on the fruit firmness (McCormick Fruit Tech; Yakima, Washington), according to the procedure reported by Pressey and Avants (1978). One had a range of 0 to $49 \mathrm{~N}$ and the other one of 0 to $120 \mathrm{~N}$. At each time interval during storage, measurements were performed on two opposite sides of five fruits. The penetrometers were fitted with $7.9 \mathrm{~mm}$ tips.

Cell wall isolation. Cell walls were isolated as described by Gross (1984) with modifications in duration of homogenization

Abbreviations. ASP, alkaline-soluble pectin; CSP, chelate-soluble pectin; HPSEC, high performance size exclusion chromatography; IV, intrinsic viscosity; M, molecular weight; MF, melting flesh; NMF, nonmelting flesh, $\mathrm{R}_{v}$, radius of gyration; WAF, weeks after flowering. 
and drying cell walls. Diced, frozen peach mesocarp (200 g) was homogenized for $2 \mathrm{~min}$ in $400 \mathrm{ml}$ of cold $80 \%$ aqueous ethanol using a Polytron homogenizer set at $\approx 14,000$ RPM (Brinkmann, Instr. Co., Westbury, N.Y.); the homogenate then was separated from the residue (cell walls) by filtering through miracloth (Calbiochem, San Diego). The residue was washed with distilled water. The cell walls were then extracted with $20 \mathrm{~mm}$ Hepes$\mathrm{NaOH}, \mathrm{pH} 7.4$, and 1 min of homogenization. Residues were suspended and incubated with constant stirring for $18 \mathrm{~h}$ at $30 \mathrm{C}$ in $150 \mathrm{ml}$ of buffer containing $150 \mu \mathrm{l} \alpha$ amylase (Sigma Type-Ia) and $50 \mu \mathrm{l}$ of toluene without homogenization. After being rinsed twice with $200 \mathrm{ml}$ of buffer, the residues were sequentially extracted with $200 \mathrm{ml}$ of 2 phenol : 1 acetic acid : 1 water (by volume, Selvendran, 1975) 1 chloroform : 1 methanol (v/v), and acetone. After acetone extraction, cell walls were lyophilized.

Pectin extraction. Lyophilized cell walls were extracted with $50 \mathrm{~mm} \mathrm{Na}$-acetate buffer (pH 6.5) containing $50 \mathrm{~mm} \mathrm{CDTA}$ at 25C for $6 \mathrm{~h}$ with constant stirring (Jarvis, 1982). Then, the residue was extracted, with $50 \mathrm{mM} \mathrm{Na}_{2} \mathrm{CO}_{3}$ containing $2 \mathrm{~mm} \mathrm{CDTA}$, and stirred for $20 \mathrm{~h}$ at $4 \mathrm{C}$ followed by $1 \mathrm{~h}$ at $25 \mathrm{C}$ and filtered. The $\mathrm{pH}$ of this last filtrate was adjusted to $\mathrm{pH} 6.5$ by the gradual addition of glacial acetic acid. Both filtrates were dialyzed exhaustively against water and lyophilized. The material from the $50 \mathrm{~mm}$ CDTA extraction was designated CSP (chelate-soluble pectin), whereas the material from the carbonate extraction was designated ASP (alkalinesoluble pectin).

Carbohydrate analysis. Each fraction, ASP or CSP, was assayed for total sugars by the phenol-sulphuric acid (PS) method (Dubois et al., 1956) and for galacturonic acid (Scott, 1979). In employing the PS method, color response against concentration was measured for glucose and galacturonic acid, whereas galacturonic acid was the standard when employing Scott's method. To obtain galacturonic acid as a percentage of total sugars, the amount of galacturonic acid was obtained from Scott's method. This amount of galacturonic was converted to absorbance by using the galacturonic acid standard curve from the PS method. The absorbance of galacturonic acid was subtracted from the absorbance of the total sample obtained from the PS method. The remainder absorbance was converted to neutral sugars in terms of glucose equivalents by using the glucose response curve obtained from the PS method.

Chromatography. Solutions ranging from 0.52 to $0.57 \mathrm{mg}$ pectin/milliliter were prepared by dissolving pectin in mobile phase, equilibrating overnight at $35 \mathrm{C}$ in capped bottles, and followed by passing through a $0.4 \mathrm{pm}$ nucleopore filter before chromatography. The mobile phase was $0.05 \mathbf{m ~ N a N O}_{3}$. The distilled water used in the mobile phase was passed through a Modulab HPLC polisher, (Continental Water Corp, San Antonio, Texas). The mobile phase was degassed before connecting to the system and inline with a model ERC 3120 degasser (Erma Optical Co., Tokyo). The solvent delivery system was Beckman Model 334 (Beckman Instruments, Palo Alto, Calif.). The nominal flow rate was $0.5 \mathrm{ml} \cdot \mathrm{min}^{-1}$. The pumping system was fitted with a Beckman pulse filter and two Waters Model M45 pulse dampers (Waters Association, Millford, Mass.), mounted on a plate and separated by $4.5 \mathrm{~m}$ of coiled capillary tubing (i.d., $0.25 \mathrm{~mm}$ ). Sample injection was with a Beckman model 210 valve. The injected sample volume was $100 \mu \mathrm{l}$. Three columns were employed in series: 1) a Waters Micro-Bondage1 EHigh $\AA$, $(300 \times 3.9 \mathrm{~mm}) ; 2)$ a Waters Micro-Bondage1 E-1000 (300 x $3.9 \mathrm{~mm}$ ) (Waters Associates); and 3) a Synchropak GPC-100 $(250 \times 4.6 \mathrm{~mm})$ (Synchrom, Linden, Ind.). Detection was online with a differential viscosity detector (DV) and a differential refractive index detector (DRI) in series. The viscosity detector was a model 100 differential viscometer (Viscotek Corp., Porter, Texas). Differential refractive index was measured with a model ERC 7810 monitor (Erma Optical Co., Tokyo). Chromatography columns were thermostated in a temperature-controlled water bath at $35 \pm 0.01 \mathrm{C}$, and the cells of the refractive index and viscosity monitors were thermostated also at 35C. Measurement of flow rate has been described previously (Fishman et al., 1987). Data acquisition was with a $25 \mathrm{MHz} .386$ personal computer equipped with a Viscotek DS-01 PC interface and Unical 3.10 software.

Curve fitting. Resolution of partially resolved chromatograms into overlapped components was accomplished with a curve fitting program developed in-house (Fishman et al., 1989a). The user interactive, command-driven software fits chromatograms to a series of Gaussian-shaped peaks. Initially, the number of peaks (up to eight), peak height (ht), one quarter peak width at half height $(\sigma)$, and position of peak maximum (max) are estimated. The final values of ht, $\sigma$, and max for each peak relative to the experimental chromatogram is determined by iteratively minimizing the sum of the squares of the residual differences between the experimental and calculated chromatograms at each point along the curve. Least squares minimization is accomplished by a nonlinear approach using the Gauss-Newton iteration technique (Draper and Smith, 1966). As was the case for 13 pectins investigated previously (Fishman et al., 1989a, 1991a), the first envelope for peach pectin could be fitted with five components or less when one or more components were missing as indicated by the absence of an refractive index (RI) signal. One iterated sigmavalue $(0.274 \mathrm{ml})$ sufficed for all five peaks. This value was close to an average experimental value of $0.254 \pm 0.007 \mathrm{ml}$ found by separately chromatographing five narrow pullulan standards ranging in molecular weight from $8.34 \times 10^{5} \mathrm{kDa}$ to $4.8 \times 10^{4} \mathrm{kDa}$. The low
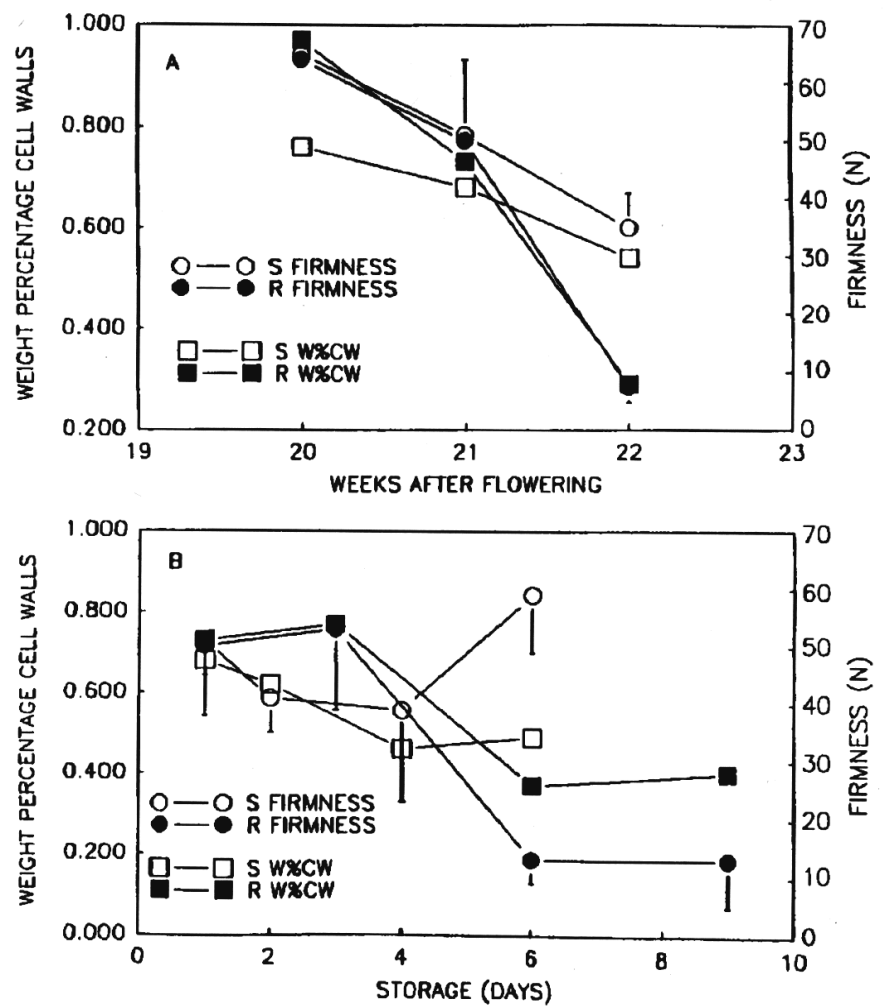

Fig. 1. Changes in the weight of cell walls as a percentage of mesocarp fresh weight and changes in firmness during (A) tree ripening and (B) storage of (S) 'Suncling' and (R) 'Redskin' peaches. 
Table 1. Weight percentage of pectin in cell walls and galacturonic acid as a percentage of total pectic sugars during tree ripening.

\begin{tabular}{|c|c|c|c|c|c|}
\hline \multirow[b]{2}{*}{ WAF } & \multirow{2}{*}{$\begin{array}{c}\text { Mesocarp } \\
\text { firmness }(\mathbf{N})\end{array}$} & \multicolumn{2}{|c|}{$\operatorname{Pectin}^{2}(\%)$} & \multicolumn{2}{|c|}{ Galacturonic acid } \\
\hline & & CSP & ASP & CSP & ASP \\
\hline \multicolumn{6}{|c|}{ 'Suncling' } \\
\hline 20 & 64 & $11.0 \pm 4.9^{x}$ & $13.7 \pm 2.3$ & $90.0 \pm 1.3$ & $87.2 \pm 2.5$ \\
\hline 21 & $50 \pm 13^{w}$ & $11.8 \pm 5.0$ & $13.8 \pm 2.3$ & $91.7 \pm 4.2$ & $84.7 \pm 4.6$ \\
\hline 22 & $34 \pm 16$ & $11.5 \pm 3.1$ & $17.2 \pm 4.6$ & $86.9 \pm 5.7$ & $79.7 \pm 6.6$ \\
\hline \multicolumn{6}{|c|}{ 'Redskin' } \\
\hline 20 & 63 & $11.0 \pm 2.7$ & $17.1 \pm 2.5$ & $89.7 \pm 5.9$ & $85.8 \pm 5.8$ \\
\hline 21 & $49 \pm 5$ & $12.1 \pm 3.2$ & $14.1 \pm 3.8$ & $91.7 \pm 4.5$ & $88.0 \pm 1.8$ \\
\hline 22 & $7 \pm 3$ & $6.9 \pm 1.8$ & $9.4 \pm 2.5$ & $62.4 \pm 7.7$ & $58.5 \pm 2.7$ \\
\hline
\end{tabular}

${ }^{\mathrm{z}}$ grams pectin/100 g cell walls (dry weight basis).

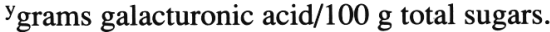

${ }^{\mathrm{x}} \mathrm{SD}$ of three colorimetric analyses.

${ }^{\mathrm{w}} \mathrm{SD}$ of 10 firmness measurements.

Table 2. Weight percentage of pectin in cell walls and galacturonic acid as a percentage of total pectic sugars during storage.

\begin{tabular}{|c|c|c|c|c|c|}
\hline \multirow[b]{2}{*}{ DAYS } & \multirow{2}{*}{$\begin{array}{c}\text { Mesocarp } \\
\text { firmness (N) }\end{array}$} & \multicolumn{2}{|c|}{$\operatorname{Pectin}^{2}(\%)$} & \multicolumn{2}{|c|}{ Galacturonic acid ${ }^{y}$} \\
\hline & & CSP & ASP & CSP & ASP \\
\hline \multicolumn{6}{|c|}{ 'Suncling' } \\
\hline 1 & $50 \pm 13^{x}$ & $11.8 \pm 5.0^{\mathrm{w}}$ & $13.8 \pm 2.3$ & $91.7 \pm 4.2$ & $84.7 \pm 4.6$ \\
\hline 2 & $40 \pm 6$ & $16.8 \pm 4.3$ & $19.5 \pm 2.7$ & $91.5 \pm 2.7$ & $81.0 \pm 4.4$ \\
\hline 4 & $38 \pm 16$ & $10.4 \pm 2.8$ & $17.9 \pm 4.1$ & $85.0 \pm 4.1$ & $78.1 \pm 6.4$ \\
\hline 6 & $58 \pm 10$ & $12.5 \pm 3.4$ & $21.5 \pm 3.7$ & $97.6 \pm 3.7$ & $81.2 \pm 4.2$ \\
\hline \multicolumn{6}{|c|}{ 'Redskin' } \\
\hline 1 & $49 \pm 5$ & $12.1 \pm 3.3$ & $14.1 \pm 3.8$ & $91.7 \pm 4.2$ & $88.0 \pm 1.8$ \\
\hline 3 & $52 \pm 14$ & $12.1 \pm 3.3$ & $21.3 \pm 5.8$ & $94.4 \pm 2.6$ & $78.0 \pm 2.1$ \\
\hline 6 & $13 \pm 4$ & $5.7 \pm 1.5$ & $9.1 \pm 2.4$ & $75.9 \pm 4.8$ & $64.6 \pm 4.4$ \\
\hline 9 & $13 \pm 8$ & $7.0 \pm 1.9$ & $11.3 \pm 3.1$ & $66.1 \pm 3.8$ & $71.3 \pm 1.5$ \\
\hline
\end{tabular}

${ }^{\mathrm{z}}$ grams pectin/100 g cell walls (dry weight basis).

y grams galacturonic acid/100 g total sugars.

${ }^{\times}$SD of 10 firmness measurements except 'Redskin' stored for 9 days in which case four measurements were taken.

${ }^{w_{S D}}$ of three colorimetric analyses.

molecular weight tail of the differential refractive index (DRI) chromatogram could be fitted by three components with a $\sigma$ value of $0.116 \pm 0.008 \mathrm{ml}$, which was measured for sucrose. For the case of ASP, the least squares minimization for the viscosity chromatogram converged rapidly once the DRI chromatogram was fitted. Values of $\sigma$ and max (the latter value corrected for dead volume between detectors) were independent of detector. Thus, for ASP viscosity chromatograms, only ht had to be iterated, since the DRI and DV chromatograms differed only in the sensitivity of their signal response to pectin. For CSP, the same values of $\sigma$ and max could not be used to obtain good fits for both DRI and differential viscometer (DV) chromatogams.

Calculation of average properties. Weight average radii of gyration $(\mathrm{Rg})$, intrinsic viscosities ([IV]), and molecular weights (M) were calculated according to standard formulas (Flory, 1953). Only the data from the envelope containing the macromolecular sized species was used in the calculations. In the case of CSP, the distributions of properties (i.e., $\mathrm{R}_{\mathrm{g}}$, [IV], or $\mathrm{M}$ ) were treated as if they were derived from continuums of molecules. For ASP, global averages were obtained by summing over the five or fewer macromolecular sized species in each distribution.

Column calibration. Congruent calibration curves were obtained by plotting $\log \mathrm{R}_{\mathrm{g}}$ or $\log [\mathrm{IV}] \mathrm{M}$ against column partition coefficients $\left(\mathrm{K}_{\mathrm{av}}\right)$ obtained for a series of narrow molecular weight distribution (MWD) pullulan standards (polydispersities ranging from 1.07 to 1.14) and broad MWD dextran standards (polydispersities ranging from 1.39 to 2.91) (Fishman et al., 1987, 1991a, 1991b). These calibration curves were used to obtain $\mathrm{R}$ and $\mathrm{M}$ for unknown pectin samples by the "Universal Calibration" procedure. According to this procedure, pectins will co-elute with dextrans and pullulans that have identical values of either $\mathrm{R}$ or product of [IV] and M. To obtain M, the product of [IV]M was divided by [IV], which was obtained as a function of $\mathrm{K}_{\mathrm{av}}$ by the online viscosity detector.

\section{Results}

Cell wall yield and firmness changes in peaches. During on-tree ripening, the weight of cell walls as a percentage of fresh weight and fruit firmness (Fig. 1A) decreased for each variety. 'Redskin', unlike 'Suncling' peaches, exhibited a dramatic acceleration of cell wall solubilization and softening in the 22nd WAF. Similarly, 'Redskin' peaches underwent a large decrease in cell wall weight and firmness between the 3rd and 6th day of storage, whereas 'Suncling' peaches did not (Fig. 1B).

Changes in percentage of pectin and galacturonic acid. During 

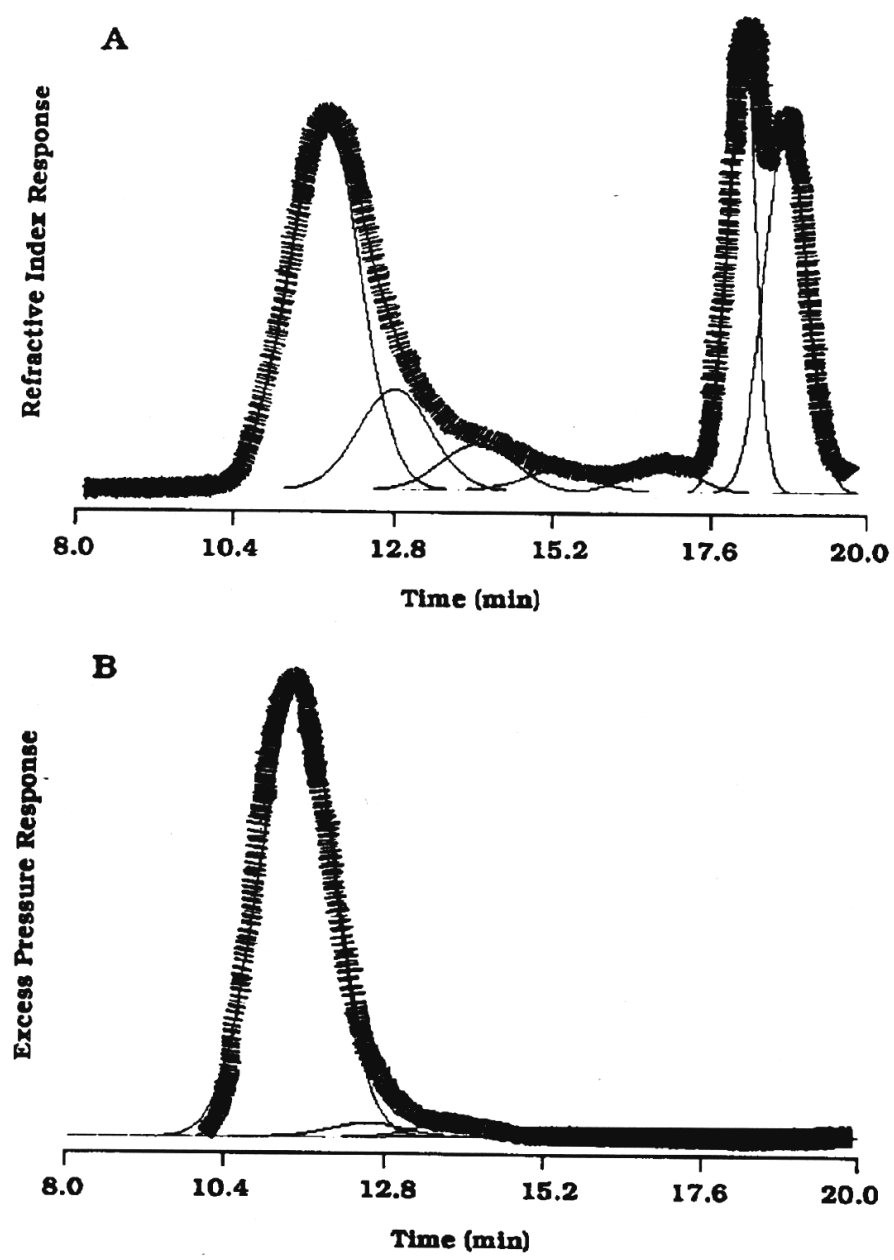

Fig. 2. Chromatograms of CSP extracted from 'Redskin' peaches picked $21 \mathrm{WAF}$. Injected concentration, $0.57 \mathrm{mg} \cdot \mathrm{ml}^{-1}$, injected volume, $100 \mu \mathrm{l}$; mobile phase, $0.05 \mathrm{M} \mathrm{NaNO}_{3}$; nominal flow rate $0.05 \mathrm{ml} \cdot \mathrm{min}^{-1}$; thick line, experimental; thin line, calculated. Detector $(\mathbf{A})$ differential refractometer $(\mathbf{B})$ differential viscometer.

3 weeks of on-tree ripening, changes in weight of pectin as a percentage of cell wall and changes in weight of galacturonic acid as a percentage of total sugar (i.e., ratio of galacturonic acid to neutral sugar) in pectin appeared minimal for 'Suncling' peaches (Table 1). 'Redskin' peaches showed an appreciable decrease in weight percentage chelate-soluble pectin (CSP) and alkalinesoluble pectin (ASP) and in the ratio of galacturonic acid to pectin neutral sugar in the 22nd WAF. During storage at 25C, percentage of cell wall pectin and the ratio of galacturonic acid to neutral sugar decreased markedly between the 3rd and 6th day of storage for CSP and ASP fractions of 'Redskin' peaches (Table 2). Minimal changes during storage in percentage of cell wall pectin and ratio of galacturonic acid toneutral sugar occurred in 'Suncling' peaches. For the two varieties, percentage ASP in cell walls was higher than percentage of CSP, whereas the ratio of galacturonic acid to neutral sugars was higher in CSP than ASP during tree ripening and storage.

Chromatography. Figures 2-5 contain typical DRI and DV chromatograms for CSP and ASP fractions from 'Redskin' and 'Suncling' peaches. These chromatograms are for samples picked $21 \mathrm{WAF}$ and frozen 1 day after being picked. The envelope for the macromolecular sized species of all the DRI traces (Figs. 2A-5A) can be reconstructed as a linear combination of five or less species as in previous studies (Fishman et al., 1989, 1991a, 1991b). Using the same values for band spreading and peak position, the DV chromatogram for the ASP (Figs. 3B and 5B), but not the CSP (Figs. 2B and 4B), can also be reconstructed as a linear combination of fewer than five macromolecular sized species. In general, these components decrease in $\mathrm{R}_{\mathrm{g}}$ (molecular size), $\mathrm{M}$, and IV as the elution time increases.

Changes in radii of gyration (molecular size). The data in Fig. 6 $\mathrm{A}$ and $\mathrm{B}$ reveal that CSP is initially much larger than ASP. In the case of 'Suncling' CSP, this difference in size is maintained throughout on-tree ripening and storage. In the case of 'Redskin' CSP, in the 22nd WAF and on the 6th day of storage, a large drop in the size of 'Redskin' CSP has taken place, so that 'Redskin' CSP and ASP are comparable in size.

Changes in intrinsic viscosity. As was true for $\mathrm{R}$ measurements, the initial IV of CSP was much larger than the IV of ASP. 'Suncling' CSP maintained a larger IV than ASP during on-tree ripening and storage, whereas 'Redskin' CSP underwent a large drop in IV in the 22nd WAF and on the 6th day of storage (Fig. 7 A and B). Thereafter the IVs of 'Redskin' CSP and ASP were similar.

Changes in molecular weight. At $20 \mathrm{WAF}$, the M of all four fractions was similar. The $M$ of 'Suncling' pectin from the two fractions was relatively constant during on-tree ripening and storage, whereas the M of CSP and ASP from 'Redskin' peaches
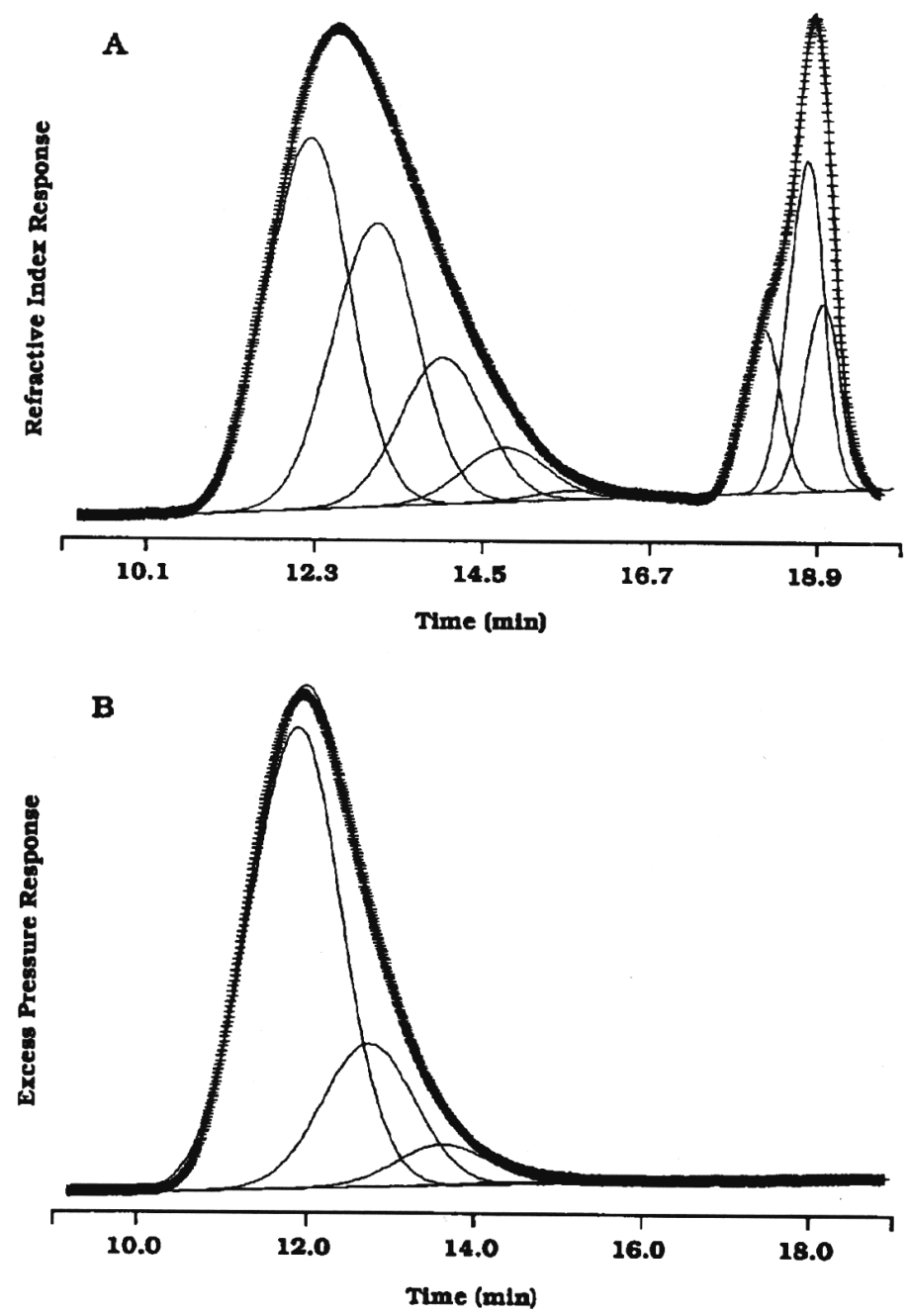

Fig. 3. Chromatograms of ASP extracted from 'Redskin' peaches picked 21 WAF. Injected concentration, $0.57 \mathrm{mg} \cdot \mathrm{ml}^{-1}$. See Fig. 2 for conditions. 
increased considerably in the 22nd WAF and by the 6th day of storage (Fig. $8 \mathrm{~A}$ and $\mathrm{B}$ ).

\section{Discussion}

Galacturonic acid as a percentage of total sugar in peach pectin is often reported to be significantly lower than the values reported in Tables 1 and 2, with the exception of 'Redskin' at $21 \mathrm{WAF}$ or 6 to 9 days of storage (e.g., Chapman and Horvat, 1990). The individual neutral sugar content (data not shown) of the samples reported in Table 1 were determined by gas chromatography (K.C. Gross, personal communication) and found to be consistent with the high galacturonic values reported in Table 1. Thus, we concluded that colorimetric estimates of sugar content in pectin were correct. Further, IVs for peach CSP were significantly higher than IVs for pectin from any other source measured in this laboratory (Fishman et al. 1989b, 1991b). Moreover, galacturonic acid content appears to be uncorrelated or negatively correlated with IV. The question arises as to what percentage of neutral sugars found in pectin isolates are covalently bonded to pectin.

We previously used high performance size exclusion chromatography (HPSEC) with computer aided curve fitting to study changes in the macromolecular sized components of tomato fruit pectin that occurred with maturity (Fishman et al., 1989a). That study paralleled the present one in that a similar scheme was used to extract the pectin components. We found that in all stages of tomato maturity, pectin was composed of a linear combination of five or fewer components (Fishman et al. 1989a). High performance size exclusion chromatography analysis before and after
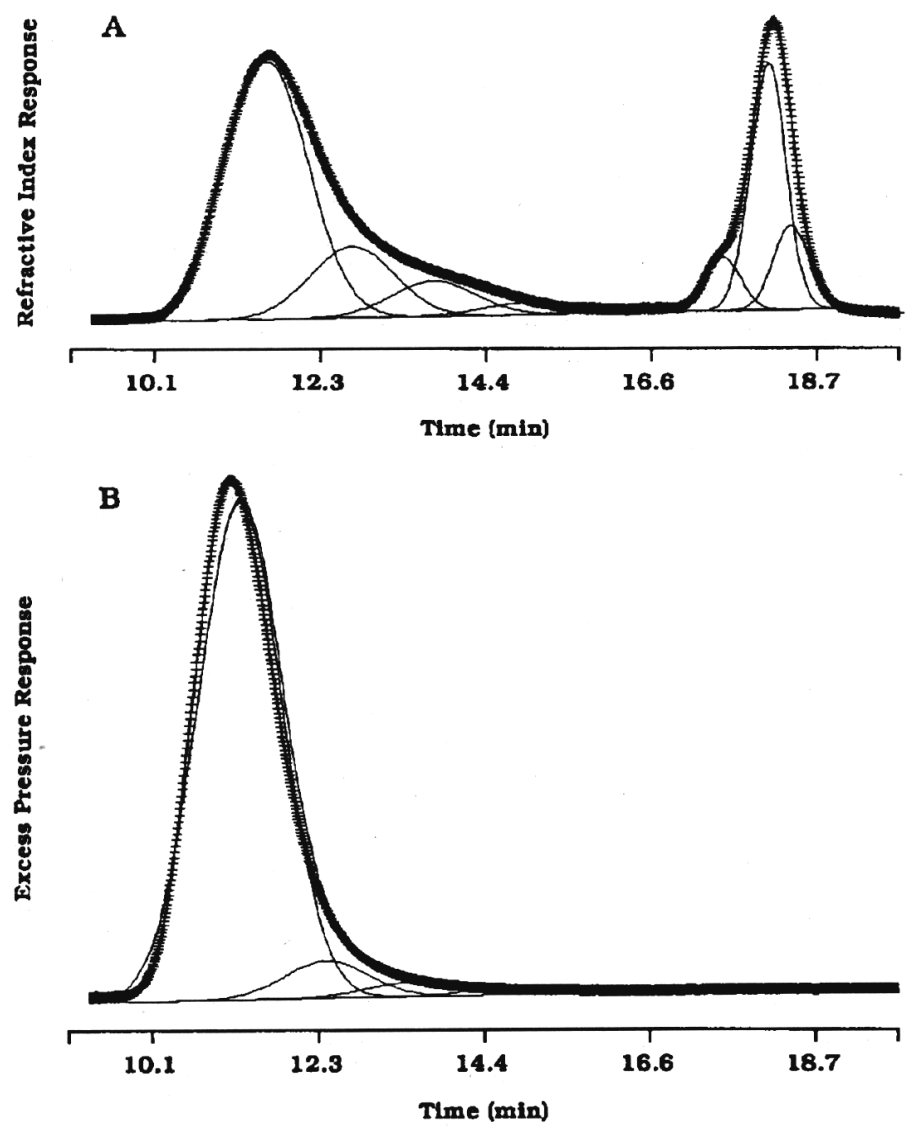

Fig. 4. Chromatograms of CSP extracted from 'Suncling' peaches picked 21 WAF. Injected concentration, $0.57 \mathrm{mg} \cdot \mathrm{ml}^{-1}$. See Fig. 2 for conditions.
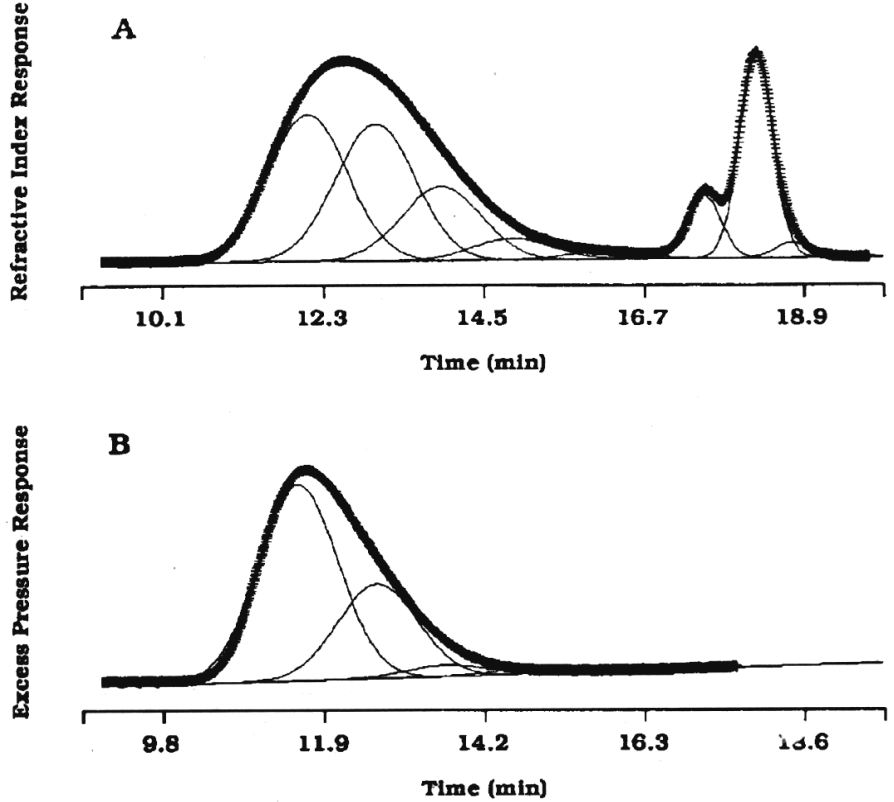

Fig. 5. Chromatograms of ASP extracted from 'Suncling' peaches picked $21 \mathrm{WAF}$. Injected concentration, $0.52 \mathrm{mg} \cdot \mathrm{ml}^{-1}$. See Fig. 2 for conditions.

dialysis against $0.05 \mathrm{M} \mathrm{NaCl}$ revealed that salt induced larger components to dissociate into smaller subunits and fragments, some of which passed through the dialysis tubing. These events were marked by chromatograms that were shifted and/or had shapes that were more skewed to longer elution times after dialysis than before (Fishman et al. 1989a). Quantitatively, the dissociation of tomato pectin was marked by a decrease in the weight average $\mathrm{R}_{\mathrm{g}}$ after dialysis, and the weight fraction of smaller components increased at the expense of larger ones. From its behavior in the presence of $\mathrm{NaCl}$, we concluded that cell wall pectin behaved as if it were an aggregated mosaic held together partially by noncovalent interactions (particularly hydrogen bonds) (Fishman et al. 1989a). Furthermore, evidence indicated that the loss of cell wall integrity (softening) could occur by mechanisms other than degradation by polygalacturonase, such as changes in the ionic strength of fluids in contact with the cell wall.

The concept that pectin is composed of five macromolecular components was confirmed in a study of pectins from twelve sources other than tomato (Fishman et al., 1991 a). In a companion study involving these same twelve pectins, using HPSEC with viscosity detection, $\mathrm{M}$ and IV of each component and overall global averages were determined (Fishman et al., 1991b). This study demonstrated that some pectin components from different sources but with the same value of $\mathrm{R}$ (i.e., these components eluted at identical times) had values of $M$ and IV that differed. These differences manifested themselves by differences in viscosity detector component areas from chromatograms comparable to those shown in the present study in Figs. 3B or 5B. Differences in $\mathrm{M}$ and IV at constant $\mathrm{R}_{\mathrm{g}}$ are possible if pectins are aggregated rods or aggregated segmented rods. Earlier studies on commercial citrus pectins had led to this same conclusion (Fishman et al. 1984, 1986, 1989b).

Recently, circular pectin microgels were visualized by transmission electron microscopy of rapidly dried aqueous solutions of 'Redskin' CSP (Fishman et al., 1992). The circular microgels were comprised of interconnecting gel networks. The connecting elements (subunits) of the network could be dissociated into rods and segmented rods when dried from $50 \%$ aqueous glycerol or $50 \mathrm{~mm}$ 

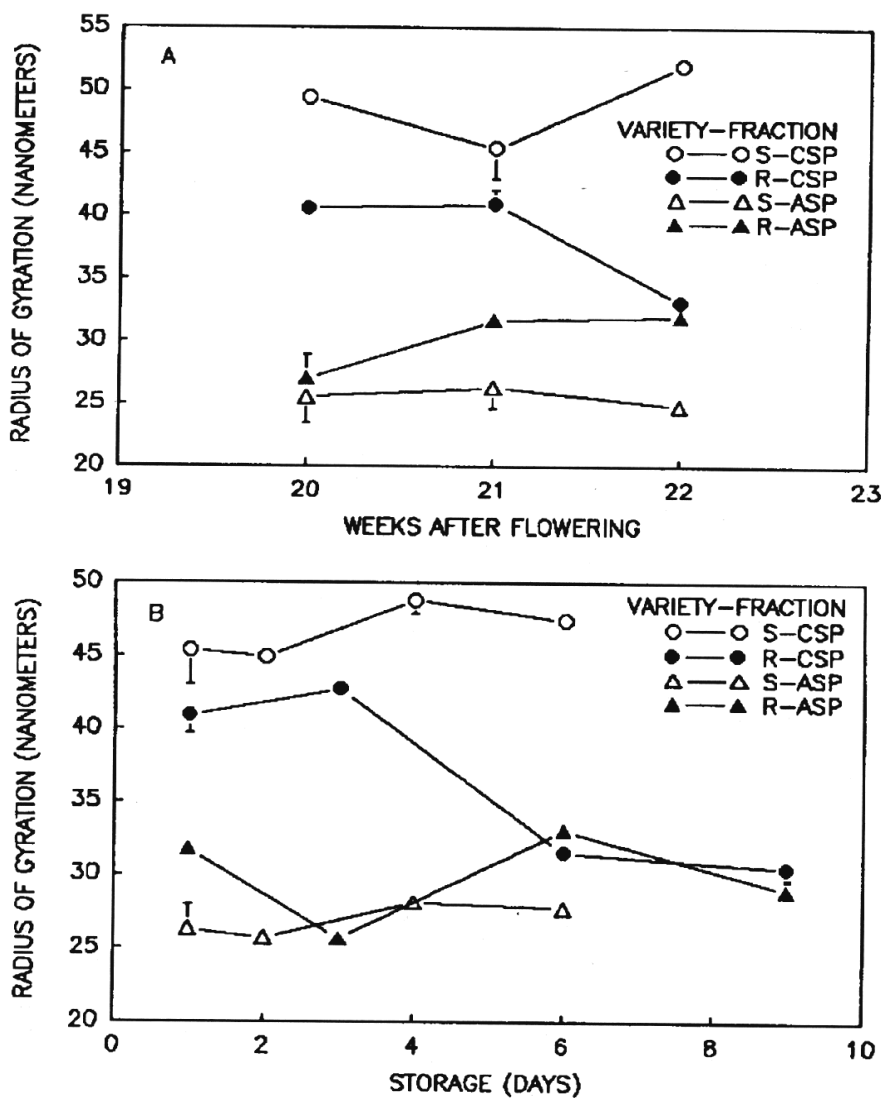

Fig. 6. Changes in radii of gyration of CSP and ASP from (S) 'Suncling' and (R) 'Redskin' peaches during (A) on-tree ripening (B) storage at $25 \mathrm{C}$.

$\mathrm{NaCl}$. The three most frequent subunits visualized by microscopy were similar in size to subunits 1 through 3 measured by HPSEC with viscosity detection. Further, based on size and molecular weight, the subunits were calculated to be aggregates about three to four pectins molecules thick.

The evidence that pectin "molecules" are in fact noncovalently bonded aggregates of smaller covalently bonded moities provides a physico-chemical basis for several important properties of pectin. These include the tendency of pectin: (i) to produce fragments that in turn may initiate various metabolic processes in the plant life cycle (Darvill et al., 1988); (ii) to undergo solvent-mediated changes in cell wall rigidity as a alternative to direct hydrolytic, enzymatic degradation (Fishman et al., 1989a, 1992); and (iii) to contribute significantly to the texture of processed and unprocessed fruits and vegetables (Fishman, 1991c). This comparative study on pectin from 'Suncling' and 'Redskin' peaches was undertaken to increase knowledge of (ii) by elucidating the effect of non- and enzymatically mediated changes on the structure of cell wall pectin.

'Redskin' and 'Suncling' peaches are edible when allowed to ripen on the tree for 21 WAF. Chapman and Horvat (1990) reported that the pectin content of 'Monroe', a MF peach, increased from $\approx 11.5$ to $20 \mathrm{WAF}$, and thereafter decreased. Pressey and Avants (1978) reported that unripe MF peaches underwent marked decreases in firmness upon ripening, and that the ripening was accompanied by rises in endo- $\alpha$ D-galacturonase activity and in water-soluble pectin. NMF peaches showed a lesser drop in firmness and a lesser rise in water soluble pectin than found for MF peaches. Moreover, unripe NMF peaches exhibited low levels of
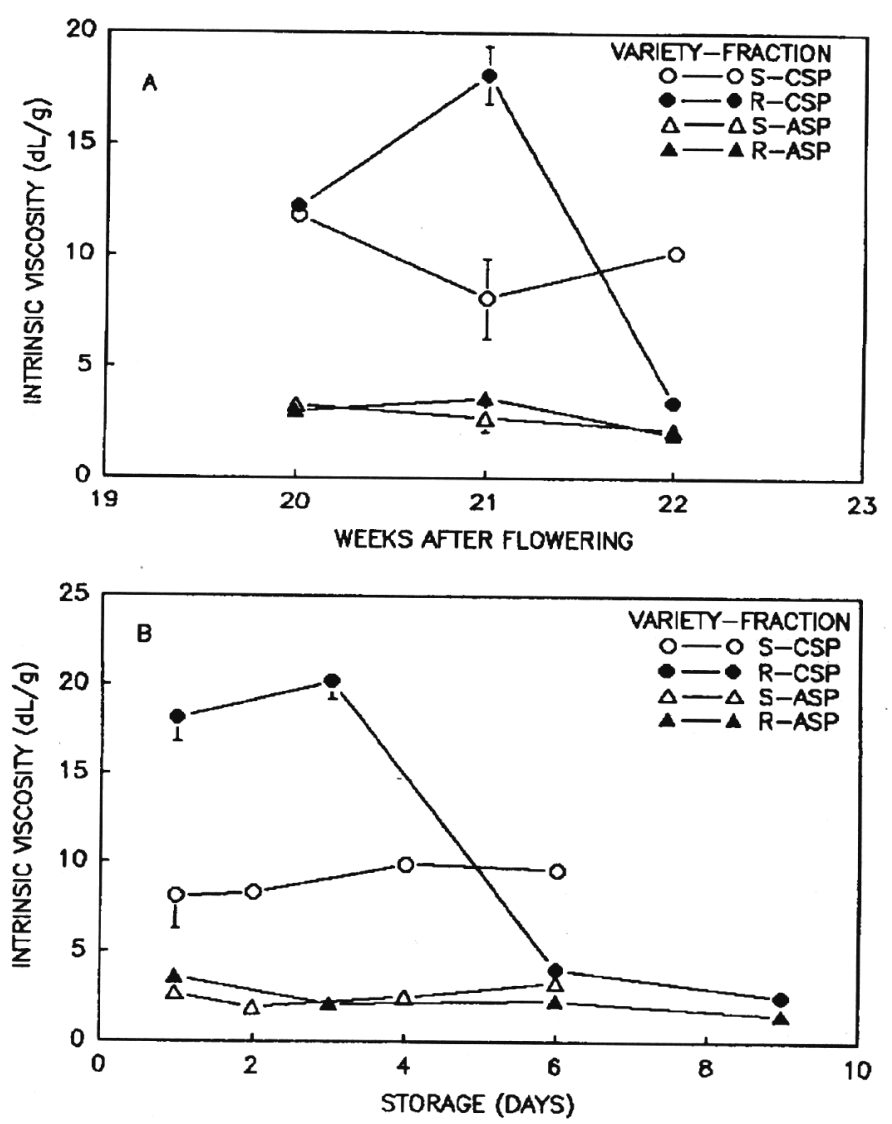

Fig. 7. Changes in intrinsic viscosity of CSP and ASP from (S) 'Suncling' and (R) 'Redskin' peaches during (A) on-tree ripening (B) storage at $25 \mathrm{C}$.

endo- $\alpha$ D-galacturonase and very slight rises in its activity upon ripening (Pressey and Avants, 1978). Our measurements of firmness and weight percentage of cell walls in the fresh tissue tend to support the findings of those cited and suggest that we study the peaches at a time when pectin structure might be undergoing major changes, particularly in the case of 'Redskin' peaches. The relatively constant percentage of pectin in cell walls and ratio of galacturonic acid to neutral sugar suggests that the net cell wall material present during on-tree ripening or storage of 'Suncling' peaches remained relatively unchanged. Thus, the softening that occurred was probably correlated with the net loss of cell wall. Initially, 'Redskin' (MF) peaches seemed to follow a course similar to that of 'Suncling' (NMF). At the end of on-tree ripening or storage, however, large drops were observed in 'Redskin' firmness, percentage of cell wall in fresh tissue, percentage of pectin in cell walls, and percentage of galacturonic acid in pectin. Thus, it appears that in addition to the net loss in total cell walls, the pectin remaining in cell walls of 'Redskin' peaches changed during the latter stages of maturation.

As was the case for compositional changes, molecular changes occurring during on-tree ripening or storage were much greater for pectin from 'Redskin' than from 'Suncling' peaches. Particularly striking were the large drops in IV and R for 'Redskin' CSP in the latter stages of on-tree ripening or during storage. Also observed in the latter stages of these experiments was an increase in the $\mathrm{M}$ for both CSP and ASP of 'Redskin' peaches. Because pectin exists as aggregated rods, it is possible for the $\mathrm{M}$ to increase and the viscosity to drop simultaneously (Fishman et al., 1991b, 1992). For example, the splitting of dimeric rods into two monomeric rods 
of equal length would halve the $M$ of each dimer but increase the viscosity of the solution due to the increase in the number of rods. Simultaneous decreases in $\mathrm{R}_{\mathrm{g}}$ and IV accompanied by an increase in $\mathrm{M}$ indicates a decrease $\mathrm{m}$ length and an increase in lateral aggregation of 'Redskin' CSP. For the case of 'Redskin' ASP, relatively constant values of $R_{g}$ and IV with time accompanied by an increase in $\mathrm{M}$ indicates an increase in lateral aggregation but no change in length. Because cell walls were isolated before pectin isolation, the pectin analyzed was not being solubilized by in vivo solubilization processes. Apparently, the lower M 'Redskin' pectins are being solubilized first and/or there was a reorganization of pectin aggregates. In the case of CSP, the longer rods were solubilized, whereas length remained relatively constant during the solubilization of ASP. Initially, CSP differed from ASP in that it was longer and its solutions were much more viscous. The difference between the two fractions was maintained during the ripening and storage of 'Suncling' peaches, whereas differences in $\mathrm{R}_{\mathrm{g}}$ and IV between 'Redskin' CSP and ASP disappeared during ripening and storage. These differences in pectin structure with time for 'Suncling' and 'Redskin' peaches tend to confirm the suggestion of Pressey and Avants (1978) that endo- $\alpha$ D galacturonase may be responsible for softening in 'Redskin' peaches but not in 'Suncling' peaches. Further, based on our evidence, the question remains open as to what process is responsible for the initial stages of softening in 'Redskin' peaches and any softening in 'Suncling' peaches. Initially, the rather small changes in weight of cell walls, and minimal changes in amount, composition, and pectin structure $\left(\mathrm{R}_{\mathrm{g}}, \mathrm{IV}, \mathrm{M}\right)$ for both varieties leads one to question whether $\alpha$-D-galacturonase is involved during the initial stages of softening, and suggests that more research on other mechanisms leading to texture-related cell wall changes need to be conducted (Gross, 1990).
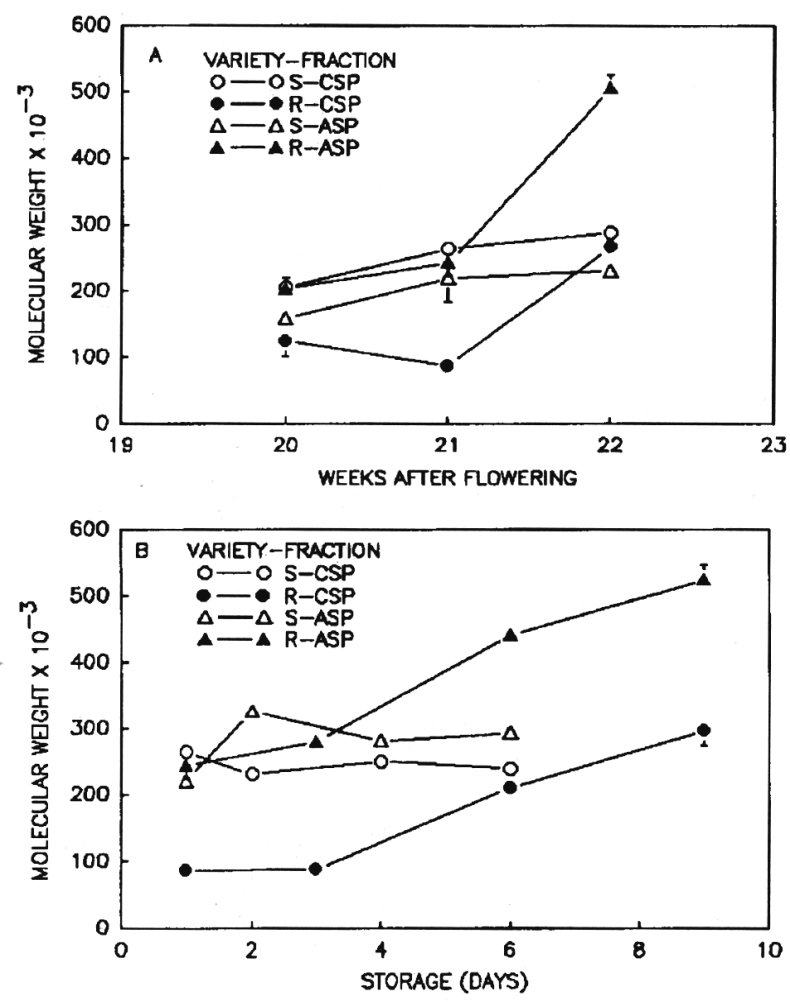

Fig. 8. Changes in molecular weight of CSP and ASP from (S) 'Suncling' and (R) 'Redskin' peaches during (A) on-tree ripening (B) storage at $25 \mathrm{C}$.

\section{Literature Cited}

Addoms, R.M., G.T. Nightingale, and M.A. Blake. 1930. Development and ripening of peaches as correlated with physical characteristics, chemical composition, and histological structure of the fruit flesh: II. Histology and microchemistry. New Jersey Agr. Sta. Bul. 507, p. 19.

Chapman, G.W. and R.J. Horvat. 1990. Changes in nonvolatile acids, sugars, pectin, and sugar composition of pectin during peach (cv. Monroe) maturation. J. Agr. Food Chem. 38:383-387.

Darvill, A., P. Albersheim, P. Buchelli, S.H. Doares, N. Doubrava, S. Eberhard, D. Gollin, J. Hahn, V. Maria, W.S. York, and D. Mohnen. 1988. In: S.C. Fry, C.T. Brett, and J.S.G. Reid (eds.). Book of abstracts and progmmme, fifth cell wall meeting, Abstr. 20, Edinburgh, Scottish Cell Wall Group c/o University of Edinburgh.

Draper, N. and H. Smith. 1966. Applied regression analysis. Wiley, New York.

Dubois, M., K.A. Gilles, J.K. Hamilton, P.A. Rebers, and F. Smith. 1956. Colorimetric method for determination of sugars and related substances. Anal. Chem. 28:350-356.

Fishman, M.L., P. Cooke, B. Levaj, D.T. Gillespie, S.M. Sondey, and R.T. Scorza. 1992. Pectin microgels and their subunit structure. Arch. Biochem. Biophys. 294:253-260.

Fishman, M.L., P.E. Pfeffer, R.A. Barford, and L.W. Doner. 1984. Studies of pectin solution properties by high-performance size exclusion. Chromatography J. Agr. Food Chem. 32:372-378.

Fishman, M.L., L.A. Pepper, and P.E. Pfeffer. 1986. Dilute solution properties of pectin, p. 57-70 In: J.E. Glass (ed.). Water soluble polymers: Beauty with performance. Adv. Chem. Ser. vol. 213. Amer. Chem. Soc., Washington, D.C.

Fishman, M.L., WC. Damert, J.G. Phillips, and R.A. Barford. 1987. Evaluation of root-mean-square radius of gyration as a parameter for universal calibration of polysaccharides. Carbohydrate Res. 160:215-225.

Fishman, M.L., K.C. Gross, D.T. Gillespie, and S.M. Sondey. 1989a. Macromolecular components of tomato fruit pectin. Arch. Biochem. Biophys. 274:179191.

Fishman, M.L., D.T. Gillespie, S.M. Sondey, and R.A. Barford. 1989b. Characterization of pectins by size exclusion chromatography in conjunction with viscosity detection. J. Agr. Food Chem. 584-591.

Fishman, M.L., Y.S. El-Atawy, S.M. Sondey, D.T. Gillespie, and K.B. Hicks. 1991a. Component and global average radii of gyration of pectins from various sources. Carbohydrate Polymers 15:89-104.

Fishman, M.L., D.T. Gillespie, S.M. Sondey, and Y.S. El-Atawy. 1991b. Intrinsic viscosity and molecular weight of pectin components. Carbohydrate Res. 215:91-104.

Fishman, M.L. 1991c. Pectic substances, p. 2039-2043. In: Y.H. Hui (ed.). Encyclopedia of food Sci. and Technol. Wiley, New York.

Flory, P.J. 1953. Principles of polymer chemistry. Cornell Univ. Press, Ithaca, N.Y.

Gross, K.C. 1984. Fractionation and partial characterization of cell walls from normal and nonripening mutant tomato fruit. Physiol. Plant. 62:25-32.

Gross, K.C. 1990. Recent developments on tomato softening. Post Harvest News and Info. 1:109-1 12.

Huber, D.J. 1983. The role of cell wall hydrolases in fruit softening. Hort. Rev. 5:169-219.

Jarvis, M.C. 1982. The proportion of calcium bound pectin in plant cell walls. Planta 154:344-346.

Postylmayr, H.L.B., S. Luh, and S.J. Leonard. 1956. Characterization of pectic changes in freestone and clingstone peaches during ripening and processing. Food Technol. 10:618-625.

Pressey, R. 1986. Polygalacturonases in higher plants, p. 157-174. In: M.L. Fishman and J.J. Jen (eds.). Chemistry and function of pectins. Amer. Chem. Soc. ser. vol. 310. Amer. Chem. Soc., Washington, D.C.

Pressey, R. and J.K. Avants. 1978. Differences in polygalacturonase composition of clingstone and freestone peaches. J. Food Sci. 43: 1415-1423.

Reeve. R.M. 1959. Histological and histochemical changes in developing and ripening peaches. II. The cell walls and pectins. Amer. J. Bot. 46:241-248.

Scott, R.W. 1979. Colorimetric determination of hexuronic acids in plant materials. Anal. Chem. 51:936-941.

Selvendran, R.R. 1975. Analysis of cell wall material from plant tissue: Extraction and purification. Phytochemistry. 14:1011-1017.

Shewfelt, A.L. 1965. Changes and variations of the pectic constitution of ripening peaches as related to product firmness. J. Food Sci. 30:573-576. 